\title{
Da catação de lixo ao contrato de prestação de serviços de coleta seletiva no município de Nepomuceno: a atuação da RECICLANEP
}

Nahara Maria Assunção de Castro ${ }^{1}$, Benedito Anselmo Martins de Oliveira ${ }^{2}$

\section{Resumo}

Este trabalho, um estudo de caso, tem como objetivo descrever toda trajetória do trabalho de catadores de materiais recicláveis no município de Nepomuceno, Minas Gerais, enfocando a significação da criação da cooperativa RECICLANEP e do estabelecimento do contrato de prestação de serviços de coleta seletiva entre esta Cooperativa e a prefeitura para os catadores. A metodologia para este estudo baseou-se no levantamento de dados primários, entrevistas semiestruturadas, elaboração de diário de campo bem como nas observações da pesquisadora, que, desde o ano de 2012, mantém contato com o grupo de catadores. Foram evidenciados benefícios sociais e melhorias nas condições de trabalho para o grupo de catadores, bem como perspectivas positivas quanto a continuidade da parceria da prefeitura e cooperativa no contrato de prestação de serviços de coleta seletiva.

\section{Palavras-chave}

Cooperativas de catadores. Coleta seletiva. Prefeitura Municipal Nepomuceno.

\footnotetext{
${ }^{1}$ Mestra em Desenvolvimento Sustentável e Extensão pela Universidade Federal de Lavras, Minas Gerais, Brasil; assistente administrativa no Centro Federal de Educação Tecnológica de Minas Gerais, Brasil. E-mail: naharamacv@gmail.com.

${ }^{2}$ Doutor em Ciência Sociais pela Universidade Federal Rural do Rio de Janeiro, Brasil; professor associado do Departamento de Ciências Administrativas e Contábeis da Universidade Federal de São João Del-Rei, Minas Gerais, Brasil. E-mail: otideneb@ufsj.edu.br.
} 


\title{
From garbage collection to the contract for the provision of selective collection services in the municipality of Nepomuceno: RECICLANEP's performance
}

Nahara Maria Assunção de Castro ${ }^{3}$, Benedito Anselmo Martins de Oliveira ${ }^{4}$

\begin{abstract}
This experience report aims to describe the entire trajectory of the work of recyclable material collectors in the municipality of Nepomuceno, focusing on the significance of the creation of the RECICLANEP cooperative and the establishment of the contract for the provision of selective collection services between this Cooperative and the municipality for collectors. The methodology for this study was based on the collection of primary data, semi-structured interviews, preparation of a field diary as well as the observations of the researcher, who, since 2012, has been in contact with the group of waste pickers. Social benefits and improvements in working conditions for the group of waste pickers were evidenced, as well as positive perspectives regarding the continuity of the partnership between the city government and the cooperative in the contract for the provision of selective collection services.
\end{abstract}

\section{Keywords}

Waste Pickers' cooperatives. Selective collect. Nepomuceno City Hall.

\footnotetext{
${ }^{3}$ Master in Sustainable Development and Extension, Federal University of Lavras, State of Minas Gerais, Brazil; administrative assistant at the Federal Center for Technological Education of Minas Gerais, Brazil. E-mail: naharamacv@gmail.com.

${ }^{4} \mathrm{PhD}$ in Social Science, Federal Rural University of Rio de Janeiro, Brazil; associate professor in the Department of Administrative and Accounting Sciences, Federal University of São João Del-Rei, State of Minas Gerais, Brazil. E-mail: otideneb@ufsj.edu.br.
} 


\section{Introdução}

A geração, destinação e disposição final de Resíduos Sólidos Urbanos (RSU) no Brasil são, atualmente, grandes problemas. Com uma população atual de, aproximadamente, 207, 8 milhões de pessoas, o país produziu em 2018, segundo Panorama de Resíduos Sólidos no Brasil, 216.629 t/dia de RSU dos quais, $199.311 \mathrm{t} /$ dia foram devidamente coletados (ALBRELPE, 2018). Além de haver uma grande disparidade de participação na coleta destes RSU por região (ALBRELPE, 2018), que pode ser explicado por diferenças de desenvolvimento econômico, o diagnóstico do Manejo de Resíduos Sólidos Urbanos (BRASIL, 2018) "apurou que, para o ano de 2018, a coleta seletiva era praticada em apenas $38,1 \%$ dos 3.468 municípios participantes" de sua pesquisa, ou seja, 2146 ou 61,9\% municípios, não separavam o material reciclável dos demais resíduos e dos rejeitos.

A Política Nacional de Resíduos Sólidos (PNRS) (BRASIL, 2010) é um marco para a gestão de resíduos no país e define a responsabilidade compartilhada pelo ciclo de vida dos produtos como um:

conjunto de atribuições individualizadas e encadeadas dos fabricantes, importadores, distribuidores e comerciantes, dos consumidores e dos titulares dos serviços públicos de limpeza urbana e de manejo dos resíduos sólidos, para minimizar o volume de resíduos sólidos e rejeitos gerados, bem como para reduzir os impactos causados à saúde humana e à qualidade ambiental decorrentes do ciclo de vida dos produtos, nos termos desta Lei. (BRASIL, 2010, grifos nossos).

A reciclagem em um sistema de gestão integrada de resíduos sólidos remete às etapas de recuperação de recicláveis dos resíduos urbanos e sua utilização como matéria-prima secundária (IPEA, 2012). Pensando nela como uma das formas de destinação ambientalmente adequada de resíduos, a responsabilidade de cada cidadão encontra-se, sobretudo, na correta separação dos resíduos sólidos, passíveis de reutilização e reciclagem, dos demais.

Separar os recicláveis garante a coleta seletiva que, quando bem executada, contribui para o aumento da vida útil dos aterros sanitários, a limpeza das cidades e a preservação do meio ambiente, através de uma menor pressão sobre os recursos naturais (RIBEIRO; LIMA, 2000), além de colaborar para o trabalho de diversos catadores de materiais recicláveis, organizados ou não em associações ou cooperativas, que realizam a coleta, triagem, separação dos resíduos e seu acondicionamento para posterior venda às industriais recicladoras e outros. Segundo o IPEA (2013, p. 19), “os catadores são responsáveis por 90\% de todo material que chega a ser reciclado no Brasil”. 
Não é possível obter um número aproximado de catadores de materiais recicláveis no Brasil, pois diversos órgãos apresentam dados distintos. O IPEA (2012) estima um valor entre 400 a 600 mil catadores. A profissão foi incluída, em 2002, na classificação brasileira de ocupações (CBO) do Ministério do Trabalho e Emprego, depois de muita luta do Movimento Nacional de Catadores de Material Reciclável (MNCR), criado em 1999 com o objetivo de articular toda categoria na busca de uma maior valorização profissional e inclusão social (MNCR, 2017).

Esses catadores, apesar de serem incluídos socialmente pelo trabalho, são, muitas vezes, excluídos pela atividade que desempenham. A profissão é subjugada e considerada marginal por estar ligada ao trabalho com o que é descartado e rejeitado pela sociedade, por isso, "sofrem preconceito e possuem baixo reconhecimento do papel que representam na economia e no meio ambiente" (MEDEIROS; MACEDO, 2006, p. 66). Para Pereira e Teixeira (2011), o reconhecimento deste problema está em construção nos diversos municípios do país, que está o inserindo na agenda de políticas públicas das mais diversas formas.

Atualmente, diversos desses catadores têm se organizado em forma de associações e cooperativas na busca de melhores condições de trabalho, por meio do amparo dado pela PNRS, que possui como um de seus instrumentos o estímulo à criação e desenvolvimento de cooperativas de catadores de materiais recicláveis (BRASIL, 2010). Porém, somente 10\% do total estimado destes encontram-se organizados destas formas (IPEA, 2012). A maioria ainda vive da coleta informal nas ruas e lixões de diversos municípios do país, vendendo tudo o que conseguem coletar para os atravessadores, que, posteriormente, vendem às empresas recicladoras e ficam com a maior parte do lucro. Pereira e Teixeira (2011, p. 911), afirmam que "é imprescindível a construção de políticas públicas que possibilitem o exercício efetivo de direitos por parte de milhares de catadores do país, que estão em situação de pobreza e vulnerabilidade social."

Essas Cooperativas de Catadores e Catadoras de Materiais Recicláveis, portanto, acabaram também se constituindo com uma dupla finalidade de caráter socioambiental: 1) solução para a gestão mais sustentável dos resíduos sólidos, um dos problemas centrais em termos de planejamento urbano e gestão pública em praticamente todas as cidades do país onde podem prestar o serviço de coleta seletiva e evitar a disposição inadequada de materiais passíveis de reciclagem; e 2) alternativa contra as condições de exclusão e desemprego de seus próprios membros (SANTOS et al., 2016), sendo, portanto, a expressão máxima de inciativas populares de grupos de pessoas marginalizadas e de bairros pobres (FRANÇA 
FILHO, 2006), que se organizam de forma coletiva, para sobreviver num mercado capitalista excludente gerador de pobreza e injustiça social (SACHS, 2008), prestando um serviço de utilidade pública.

Organizam-se por meio de princípios da economia solidária, por isso, diferenciam-se de uma empresa privada capitalista, por não praticarem a venda da força de trabalho de seus membros, terem os meios de produção pertencentes a todos eles, os ganhos de cada um definidos por critérios deliberados em assembleia e disporem da autogestão, ou gestão democrática como a principal forma de administrá-las (SINGER; SOUZA, 2000).

As administrações públicas municipais têm contratado essas cooperativas de catadores para prestação de serviços de coleta seletiva, fundamentadas na Lei ${ }^{\circ} 11.445$ (BRASIL, 2007), que estabelece diretrizes nacionais para o saneamento básico e que alterou o inciso XXVII do caput do artigo 24 da Lei 8.666, Licitações e Contratos da administração pública (BRASIL, 1993), que torna dispensável o Processo Licitatório para contratação daquelas.

O êxito da gestão compartilhada dos resíduos sólidos, conforme preconiza a PNRS, requer das prefeituras municipais o comprometimento com a inclusão social dos catadores, a inserção efetiva destes agentes nos programas de coleta seletiva, além do reconhecimento das externalidades sociais e ambientais da atividade de catação. (IPEA, 2013, não paginado).

Porém, muitos desses catadores, organizados ou não em cooperativas, ainda realizam esse trabalho sem nenhuma contraprestação do poder público municipal em muitas cidades do país. O MNCR propõe ao poder público a:

definição e implantação, em nível nacional, de uma política de coleta seletiva que priorize o modelo de gestão integrada dos resíduos sólidos urbanos, colocando os mesmos sob a gestão dos empreendimentos dos Catadores de Materiais Recicláveis. (MNCR, 2001).

Cooperativas como a Cooperativa de Catadores de Recicláveis de Nepomuceno (RECICLANEP), segundo Besen e Ribeiro (2007), geralmente, iniciam suas atividades em parceria com as prefeituras, que oferecem a maior parte da estrutura necessária para a concretização dos trabalhos a serem executados. Zanin e Gutierrez (2011) informam que a maioria dos empreendimentos econômicos solidários de catadores não possui sede própria o que indica que grande parte deles encontra-se dependentes de assistência. Por isso, para incluir os catadores na gestão integrada dos resíduos sólidos, que em sua maioria já vem executando o serviço de coleta seletiva, nos diversos municípios do país de maneira informal e sem custos para a Administração, é necessário que as prefeituras, além de adotarem o processo de dispensa de licitação para contratação, tenham comprometimento na 
implementação de uma série de ações na estruturação e até mesmo criação de cooperativas (LIMA, 2013; MNCR, 2009; PINHEL, 2013).

Este artigo possui como objetivo compreender, por meio de uma descrição linear e temporal, o papel da prefeitura Municipal de Nepomuceno, Minas Gerais, dos movimentos sociais e das organizações não governamentais na ação de saída dos catadores de materiais recicláveis do extinto lixão do município até o estabelecimento do contrato de prestação de serviços de coleta seletiva, destacando as conquistas sociais e os benefícios econômicos do trabalho cooperativo, bem como os desafios e perspectivas para uma gestão de resíduos sólidos, com a inclusão dos catadores, mais sustentável no município.

Ao relatar como foi realizada a saída dos catadores do lixão até a constituição do contrato de prestação de serviços entre a Cooperativa RECICLANEP e o município de Nepomuceno, este trabalho pode tornar-se um indicador para subsidiar outros municípios que queiram estabelecer contratos similares, garantindo assim, um referencial para que outras cidades tenham êxito na gestão dos resíduos de forma mais sustentável, incluindo socialmente os catadores, de forma a emancipá-los e protegendo o meio ambiente, sempre com a orientação da Política Nacional de Resíduos Sólidos.

Para isso, ele foi estruturado da seguinte maneira: esta introdução, explicitando um pequeno referencial teórico, que embasa a discussão desenvolvida; o percurso metodológico do levantamento de dados e entrevistas semiestruturadas realizadas. Subsequentemente e divido em quatro seções, são discutidos os resultados alcançados na pesquisa, destacando as falas dos atores sociais entrevistados e, logo depois, apresentadas as considerações finais e as referências empregadas.

\section{Percurso metodológico}

O presente trabalho parte de uma dissertação de mestrado, trata-se de uma pesquisa do tipo estudo de caso.

Com maior enfoque na importância do contexto dos objetos envolvidos, que neste trabalho serão chamados atores sociais, foi possível elaborar uma estrutura metodológica qualitativa com objetivo descritivo. Os dados foram levantados por meio de embasamento teórico-empírico e se processaram conforme as etapas abaixo: 
$1^{\text {a }}$ etapa: Levantamento de dados primários.

Quadro 1 - Relação de documentos primários levantados durante a pesquisa

\begin{tabular}{|c|c|c|}
\hline Documento & Do que se trata & Fonte \\
\hline $\begin{array}{l}\text { Processo } \text { Administrativo } \mathrm{n}^{\circ} \\
005 / 2014 \quad \text { e Processo } \\
\text { administrativo } \mathrm{n}^{\circ} 004 / 2017\end{array}$ & $\begin{array}{l}\text { Dispensa de Licitação para } \\
\text { contratação da RECICLANEP na } \\
\text { prestação de serviços de coleta } \\
\text { seletiva em Nepomuceno. }\end{array}$ & $\begin{array}{l}\text { Secretaria Municipal } \\
\text { de Administração e } \\
\text { Recursos Humanos }\end{array}$ \\
\hline 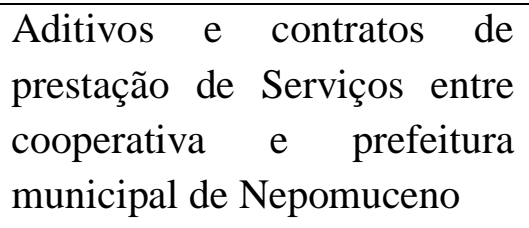 & $\begin{array}{l}\text { Estabelece as cláusulas do } \\
\text { contrato para a prestação de coleta } \\
\text { seletiva no município pela } \\
\text { RECICLANEP. }\end{array}$ & $\begin{array}{l}\text { Secretaria Municipal } \\
\text { de Agricultura e Meio } \\
\text { Ambiente }\end{array}$ \\
\hline $\begin{array}{l}\text { Notas fiscais de venda da } \\
\text { Cooperativa RECICLANEP } \\
\text { nos anos de } 2017 \text { e } 2018 \text {. }\end{array}$ & $\begin{array}{l}\text { Quantitativo, em } \begin{array}{r}\text { toneladas, de } \\
\text { materiais }\end{array} \\
\text { comercialáveis } \\
\text { RECICLANEP e seus valores } \\
\text { monetários. }\end{array}$ & $\begin{array}{l}\text { Assessoria jurídica da } \\
\text { Prefeitura Municipal } \\
\text { de Nepomuceno }\end{array}$ \\
\hline
\end{tabular}

Fonte: A autora (2019).

Os Processos Administrativos de no 005/2014 e 004/2017, que tratam da Dispensa de Licitação para contratação da RECICLANEP, tiveram como fundamento legal o Art. 24, inciso XXVII da Lei Federal de Licitações e Contratos (BRASIL, 1993) e contêm: Atas de Constituição e alteração de Membros da Cooperativa; Estatuto Social; Relatórios Socioeconômicos dos Cooperados e Cooperadas; Documentação comprovando que a Cooperativa encontra-se legalmente instituída; e demais documentos que instruem os processos (BRASIL, 1993).

$2^{a}$ etapa: Entrevistas semiestruturadas.

De acordo com Triviños (1987), esse tipo de entrevista possibilita que os atores sociais em evidência na pesquisa tenham liberdade e espontaneidade para falar de questões que vão além daquelas já pré-estabelecidas pelo pesquisador. Gil (2008) entende que durante o processo da entrevista as respostas apresentadas pelos atores sociais podem se revelar incompletas e obscuras, daí a importância do pesquisador poder evadir-se de seu roteiro garantindo assim o enriquecimento de seu trabalho. 
Em relação às medidas éticas de pesquisa, todos os entrevistados assinaram o "Termo de Consentimento Livre e Esclarecido", exigência do Comitê de Ética da Universidade Federal de Lavras, que aprovou a execução da pesquisa em 5 de outubro de 2018.

Após análise de diário de campo elaborado e a leitura flutuante (BARDIN, 2016) em todos os documentos primários, foram elaborados os roteiros das entrevistas, que puderam ser produzidos com um maior direcionamento aos objetivos específicos buscados na pesquisa, visto que as informações contidas naqueles demonstraram-se relevantes para o entendimento do contexto em que a cooperativa foi criada e como sua parceria com a Prefeitura foi estabelecida.

Aqui vale destacar que, no diário de campo, foram registrados todos os momentos em que a pesquisadora esteve em contato com membros da Cooperativa, agentes mobilizadores, além dos servidores da Prefeitura envolvidos com a Gestão dos Resíduos Sólidos no Município de Nepomuceno. Dentre estes momentos, a pesquisa alterou-se ora entre uma observação participante e ora em uma observação não participante.

Em muitas oportunidades a pesquisadora pôde estar presente, como ouvinte, em reuniões entre cooperativa e Secretaria Municipal de Agricultura e Meio Ambiente e com a Cooperativa e integrantes da Rede Sul-Sudoeste ${ }^{5}$ - uma Cooperativa de segundo grau, que agrega outras Cooperativas e da qual a RECICLANEP faz parte, caracterizando uma observação não participante, em que, segundo Gil (2008), o pesquisador apenas observa os fatos de forma espontânea, "mais como um espectador que um ator" (GIL, 2008, p. 101). Porém, em outras situações esteve diretamente envolvida nas atividades cotidianas da Cooperativa: participando de reuniões entre servidores municipais executantes da coleta de lixo, catadores, catadoras e Secretaria de Agricultura e Meio Ambiente, promovendo uma intervenção participativa e dialógica, de forma a contribuir para a solução de conflitos relatados pelos cooperados da RECICLANEP na execução da coleta de resíduos do município, bem como participando ativamente de mobilizações sociais para a coleta seletiva, organizadas pela Cooperativa com o apoio da Prefeitura, tipificando, então, a observação como participante, aquela que "consiste na participação real do conhecimento na vida da comunidade, do grupo ou de situação determinada. Neste caso, o observador assume, pelo menos até certo ponto, o papel de membro do grupo" (GIL, 2008, p. 103).

\footnotetext{
${ }^{5}$ A Rede Sul-Sudoeste de Minas Gerais: Central de Associações e Cooperativas de Materiais Recicláveis e Reutilizáveis Ltda. foi estruturada por meio do Projeto Novo Ciclo, uma parceria da Empresa Danone com o Instituto Nenuca de Desenvolvimento Social - INSEA, com o Movimento Nacional dos Catadores de Materiais Recicláveis e a Fundação Avina. Disponível em: http://www.insea.org.br/novociclo/jornal_novociclo_02_ WEB.pdf
} 
A partir de 2018, a pesquisadora também passou a ser membro titular do Conselho Municipal de Conservação do Meio Ambiente (CODEMA) e, em 2019, parte do grupo gestor selecionado pelo Instituto de Gestão de Políticas Sociais (GESOIS) ${ }^{6}$ para execução das ações previstas na ampliação da coleta seletiva municipal, onde atuou na aplicação de questionários participativos na cooperativa.

Os roteiros das entrevistas foram elaborados após análise do diário de campo e a leitura flutuante (BARDIN, 2016) em todos os documentos primários, que jogaram luz aos objetivos específicos buscados na pesquisa, permitindo a composição de perguntas mais densas e elaboradas.

Para escolha dos atores sociais entrevistados foi adotada a amostragem não probabilística, aquela em que, segundo Gil (2008, p. 94), “consiste em selecionar um subgrupo da população que, com base nas informações disponíveis, possa ser representativo de toda a população", que na pesquisa refere-se: 1) aos cooperados; 2) aos servidores da Prefeitura, considerados para estes últimos, tantos os que já foram como os que ainda estão envolvidos, nas relações com a Cooperativa ou com seus membros antes de sua criação.

Nenhum entrevistado foi identificado pelo nome, por isso, a pesquisa preocupou-se em manter sigilo e anonimato de todos eles. Dessa forma, cada um dos cinco entrevistados na Cooperativa foi denominado ao longo do trabalho por meio dos seguintes nomes fictícios: Maria, Vera, Madalena, João e José. Já para os entrevistados na Prefeitura, a identificação foi realizada da seguinte maneira: Secretário de Obras e Serviços Públicos, Analista de Políticas Públicas e Biólogo. Como método de análise dos dados, a pesquisa valeu-se da análise de conteúdo, "técnica de pesquisa que trabalha com a palavra, permitindo de forma prática e objetiva produzir inferências do conteúdo da comunicação de um texto replicáveis ao seu conteúdo social" (CAREGATO; MUTTI, 2006, p. 682). Para isso, foram conduzidas as seguintes etapas conforme descreveu Triviños (1987, p. 161): pré-análise, descrição analítica e interpretação inferencial.

A pré-análise sucedeu-se após a junção de todos os documentos primários e leitura dos diários de campo, que foram organizados e lidos para construção do roteiro de entrevistas semiestruturadas. Logo após, todas as informações levantadas nas falas dos entrevistados, permitiram o estabelecimento de cinco categorias de análise: 1) benefícios econômicos da parceria entre Cooperativa e Prefeitura; 2) Melhorias sociais aos cooperados; 3) sustentabilidade urbana e 4) desafios e possíveis conflitos na parceria.

\footnotetext{
${ }^{6}$ Disponível em: http://gesois.org.br/novo/apresentacao.php. Acesso em: 11 mar. 2019.
} 
Com a delimitação das categorias, os resultados obtidos puderam ser evidenciados e discutidos nas seções que seguem logo abaixo.

\section{O processo de instituição da RECICLANEP}

Há muitos anos, em Nepomuceno, diversas narrativas de munícipes relatavam fatos e acontecimentos envolvendo pessoas que já trabalhavam no lixão da cidade. Algumas destas pessoas levavam para o local seus filhos/as, que, acompanhando seus pais e mães na atividade de catação, posteriormente, também começaram na mesma atividade, conforme informou uma das Catadoras ao ser indagada sobre o porquê tornou-se uma catadora.

Ahh, eu vinha pro lixão com a mãe desde pequenininha. A mãe sempre coletou. Eu não catava igual eles catavam, tinha as pessoas bem mais velhas, mas eu sempre vinha pro lixão. Desde pequena. Desde os meus 12, 13 anos. Vinha cedo e ajudava a mãe catar, ficando brincando próxima a ela, mas não trabalhava como eles. (COOPERADA MARIA).

Anteriormente ao ano de 2010, por meio de um Termo de Ajustamento de Conduta com o Ministério Público, a Prefeitura Municipal de Nepomuceno comprometeu-se com este órgão do Poder Judiciário em empreender medidas para retirada dos catadores que, no lixão, estavam atuando na catação de materiais recicláveis de forma insalubre, expostos a substâncias contaminantes e em contato com animais como urubus, insetos e ratos, transmissores de diversas doenças.

No início, tentativas não conseguiram reverter o problema, pois a medida adotada constitui-se de doações de cestas básicas aos catadores em troca da não permanência no local. Ação não praticada por eles, que continuaram a executar o trabalho da catação de materiais recicláveis. Esta atitude da Administração, segundo o Analista de Políticas Públicas entrevistado, apresentou um caráter assistencialista que em nada mudaria a situação de dependência do trabalho no lixão.

a pessoa precisa da cesta básica pra se alimentar, mas também precisa de energia elétrica pra ligar uma geladeira, água pra tomar banho... então não é só uma cesta básica. Ao meu ver, é uma medida paliativa, por isso que o acordo (de não ir mais ao lixão) não foi cumprido (ANALISTA DE POLÍTICAS PÚBLICAS).

Assim, considerando que as medidas até então adotadas não surtiram os efeitos desejados, uma nova administração municipal, por meio de alguns de seus servidores, sugeriu 
outra abordagem ao problema. Por meio do trabalho de assistentes sociais, os catadores atuantes no lixão foram convencidos de que poderiam regularizar a situação insalubre e informal do trabalho que estavam executando. De acordo com o Analista de Políticas Públicas, todos eles foram cadastrados na Secretaria de Desenvolvimento Social para terem acesso a políticas públicas de transferência de renda. Para não continuar no assistencialismo, o grupo passou a ser monitorado por meio de ações que pudessem organizá-los. Ainda de acordo com ele, reuniões que pudessem abordar temas de interesse do grupo passaram a ser feitas e foram eleitos representantes, um homem e uma mulher, para conhecerem o trabalho de catadores de municípios próximos. Atividades que durante as entrevistas semiestruturadas, foram também citadas por uma das catadoras:

no começo também teve um apoio da assistência social. Ele (Analista de Políticas Públicas) chegou, apoiou, mostrou algumas cooperativas. Foi eu e outro catador em umas cooperativas. Mesmo no lixão ele convocava essas reunião, aí nós ia, né! Era muita gente nessa época. (COOPERADA MADALENA).

Desta forma, no ano de 2011, com a ajuda da Prefeitura, a RECICLANEP foi criada. Porém, acostumados ao trabalho informal, realizado de forma individual e até mesmo competitivo, o grupo de 22 cooperados, que assinaram a ata de constituição da cooperativa, passou a encontrar muita dificuldade em organizar de forma coletiva as suas atividades. Eles não possuíam nenhuma habilidade com a comercialização dos materiais, pois, até então, vendiam todo material que conseguiam coletar a um atravessador da própria cidade que pagava a eles um preço abaixo do praticado no mercado. O Analista de Políticas Públicas destaca que, neste período, "brigavam por sacolinha, por material reciclável. Brigavam por território. Não podia entrar no território do outro".

À vista disso, a Prefeitura, por meio de um Engenheiro da Empresa SERQUIP tratamento de resíduos, que estava a trabalho na cidade, elaborando um projeto para adequação ambiental do lixão, teve a oportunidade de entrar em contato com o Instituto Nenuca de Desenvolvimento Sustentável (INSEA) ${ }^{7}$ e realizar com ele um convênio, a fim de que os catadores fossem auxiliados no processo de trabalho cooperativo e autogestionário.

O INSEA, juntamente com o MNCR e com o apoio da empresa DANONE, incluiu o Município de Nepomuceno no Projeto Novo Ciclo, cujo objetivo era possibilitar o processo

\footnotetext{
${ }^{7}$ Organização não governamental de âmbito nacional, sem fins lucrativos, voltada para a assessoria técnica e parceira junto a grupos comunitários, empresas, ONGs e à Administração Pública, na criação e no desenvolvimento de modelos de gestão ambiental tendo como pressuposto básico a inclusão social. Disponível em: http://www.insea.org.br/ quem-somos/. Acesso em: 22 jan. 2019.
} 
organizativo de catadores por meio das seguintes ações: "1) implantação e fortalecimentos dos programas de coleta seletiva solidária; 2) capacitação técnica dos catadores; 3) educação ambiental; 3) mobilização social e; 4) a constituição de uma Rede de associações e cooperativas da região" (MARTINS, 2017, p. 69).

Com a assessoria de técnicos sociais e catadores mobilizadores contratados, o Projeto Novo Ciclo ajudou a constituir os Fóruns Lixo e Cidadania em diversas cidades do Sul de Minas Gerais, além de estratégias para retirada de catadores ainda exercendo suas atividades em lixões e programas de implementação e/ou revitalização da Coleta Seletiva (MARTINS, 2017). Ações que segundo Martins (2017, p. 58) foram realizadas, por meio da pedagogia do trabalho associado que produz:

um processo de emancipação social, que possibilita desenvolver novos sentidos,
maneiras de pensar e ver a vida e de se relacionar com o mundo. Há uma disposição
para o diálogo e para as trocas de saberes, construída no dia a dia do trabalho, de
modo que as experiências vão oferecendo condições de fortalecimento do trabalho
coletivo e da luta política.

Em Nepomuceno, o Fórum Lixo e Cidadania não se realizou, no entanto, já mais organizados e mais habilitados ao trabalho coletivo por meio das ações do Projeto Novo Ciclo e das iniciativas da Prefeitura, foi por ela cedido à Cooperativa um galpão que havia sido construído em 2005, com cerca de $5.000 \mathrm{~m}^{2}$, à margem da Rodovia BR-265, distante cerca de $1.500 \mathrm{~m}$ da área urbanizada da cidade, para abrigar uma usina de reciclagem estruturada com: baias para disposição dos recicláveis, banheiros, refeitório, escritório, um grande terreiro de concreto, além de uma esteira de triagem e prensa - equipamentos que haviam sido adquiridos pela Prefeitura, por meio de um Convênio com a Fundação Nacional de Saúde (FUNASA).

O trabalho executado no lixão era precário e insalubre, oferecendo grandes riscos aos catadores, que não tinham acesso a estrutura mínima para descanso, necessidades básicas, alimentação e organização administrativa. Trabalhando no galpão cedido pela Prefeitura, eles passaram a dispor de condições estruturais que denotaram ao trabalho maior dignidade ao passarem a dispor de banheiros e escritórios para organização do trabalho administrativo, além de melhorias nas condições ergonômicas de execução do trabalho de triagem com o uso de esteiras e agregação de valor ao material coletado com o uso de prensa.

É importante evidenciar que a esteira de triagem, embora disponível para o trabalho da Cooperativa desde sua formação, só pôde entrar em operação em setembro do ano de 2018, devido à ausência de um transformador trifásico de energia, que foi instalado pela administração municipal atual (2017-2020). Antes disso, todo material da coleta seletiva na 
cidade era despejado pelo caminhão diretamente no chão, causando desconforto para os catadores durante a execução da triagem.

Durante as entrevistas foi afirmado por um dos cooperados entrevistados que a saída do lixão melhorou substancialmente as condições de saúde para o trabalho, relatando o trabalho em cooperativa como menos propenso a contato com bactérias e materiais contaminantes.

A cooperativa mudou o grupo inteiro, porque antes era o lixo, que era custoso. Era mão com muitas bactérias, a gente encontrava muitas coisas. A cooperativa melhorou muito nossa vida. Melhorou de 0 a 100. (COOPERADO JOÃO).

Em setembro de 2013, com a ajuda do INSEA e o apoio da Prefeitura, por meio das Secretarias de Educação, Saúde e Procuradoria, uma ação pública de mobilização social no município foi realizada para informar a população do início da coleta seletiva que, então, seria realizada pelos catadores. A Prefeitura cedeu aos cooperados um motorista, caminhão e combustível para coleta que passou a ser executada porta a porta.

É importante observar que houve um período (entre 2011 e 2013) em que os Catadores, já organizados em cooperativa, ainda não realizavam a coleta seletiva porta a porta na cidade. Nas entrevistas, as cooperadas Maria, Vera e Madalena relataram que, nesse intervalo, o trabalho de coleta seletiva deixou de ser feito em sua integralidade no lixão e passou a se concentrar no terreiro de concreto da Cooperativa, em que o caminhão da coleta de lixo convencional do Serviço de Municipal de Limpeza Urbana depositava todos os resíduos recolhidos na cidade que, então, eram triados e separados pelos catadores, que passaram a receber um subsídio assistencial de $\mathrm{R} \$ 360$ reais/mês da Prefeitura para executar a coleta seletiva desta forma.

A atuação do INSEA possibilitou à Cooperativa um aperfeiçoamento no trabalho de autogestão e a inserção numa rede de comercialização dos materiais recicláveis, a Rede SulSudoeste, que a projetou para outros níveis e mercados de comercialização dos recicláveis coletados.

Nós dava nossa material agora nós recebe um preço legal. Agora nós tem até como negociar. Hoje são os comprador que liga pra gente pra poder comprar! Antes, nós que brigava pra eles pegarem nossa material. (COOPERADA VERA).

A inexistência do trabalho subordinado foi identificada pelos catadores como um incremento positivo na execução de suas atividades na Cooperativa, de forma a promover 
independência e liberdade como a de quem exerce uma atividade autônoma, mas que "não significa cada um fazer o que bem entender, mas poder seguir regras formuladas entre todos os cooperados" (PINHEL, 2013, p. 129), conforme esclarece o cooperado João:

na roça, no lixão era serviço braçal comum, rural. Tinha o defeito da pessoa mandar na gente, né?! A gente tinha patrão, tinha hora de chegar, de parar, tinha hora limitada. Aqui a gente acabou, decidiu com o grupo, estamos cansados, vamos embora! É uma melhora pra gente. É um serviço braçal, cansativo, repetitivo, não muda, mas nós consegue controlar. (COOPERADO JOÃO).

Assim, as ações da Prefeitura de retirada dos catadores do lixão e tentativas iniciais de organizá-los, oferecendo suporte estrutural para o trabalho por meio de apoio de projetos de coleta e reciclagem de materiais financiados pela FUNASA que, somadas as do INSEA e do MNCR dentro do Projeto Novo Ciclo, foram fundamentais para o desenvolvimento de uma identidade coletiva no grupo de Catadores que não existia no trabalho realizado no lixão. Segundo a entrevistada Vera, "antes era cada um por si, agora, aqui, por exemplo, se eu tentar puxar o tapete da outra eu também caio. Não tem como ninguém puxar o tapete um do outro, então, virou aquele conjunto em família”.

Ao serem questionados sobre o que o trabalho do INSEA proporcionou ao grupo, os cooperados entrevistados afirmaram: "Aprender ser profissional pela nossa área e nós somos profissionais pela nossa área" (COOPERADO JOÃO); "E quando a gente trabalhava no lixão era muito criticado, né! Ah, essa pessoa trabalha no lixo!” (COOPERADO JOSÉ); "Desfaziam de nós, né! Hoje que nós têm nossa empresa aberta, registrada, acho que no sul de Minas é a maior que tem" (COOPERADO JOÃO).

Com as falas acima foi possível compreender que, para além do reconhecimento profissional e renda, a Cooperativa também representa uma opção política e ideológica a todos.

\section{O estabelecimento do contrato de prestação de serviços de coleta seletiva entre a} RECICLANEP e a Prefeitura de Nepomuceno

Em janeiro de 2014, a RECICLANEP assinou seu primeiro contrato de prestação de serviço de coleta seletiva com o munícipio, passando a executá-la porta a porta em $100 \%$ da área urbana da cidade e no povoado de Santo Antônio do Cruzeiro, que fica na Zona Rural, sendo, por isto, remunerada. O segundo aditivo ao contrato, assinado em janeiro de 2017 estabeleceu um repasse de $\mathrm{R} \$ 217.252,82$ reais à cooperativa até 12 de janeiro do ano de 
2019. Esse aditivo garante que sejam recolhidos, por mês, no município, ao menos 18 toneladas de materiais recicláveis, dentre um volume de produção estimado pela Secretaria de Obras Públicas e Serviços Urbanos de 35 a 45 toneladas/mês. A Cooperativa consegue alcançar valores sempre maiores ao estipulado, entretanto, na maioria das vezes, sempre abaixo do intervalo médio de produção mensal estimado pela Secretaria de Obras e Serviços Públicos do Município.

Para as cooperadas Vera e Madalena esses valores sempre abaixo da produção mensal do município indicam que a população deve possuir um maior comprometimento na separação do material passível de reciclagem daquele que deve ir para o lixo convencional. Na cooperativa, esse trabalho de mobilização social é realizado diariamente pelos catadores, que atuam mais próximos aos cidadãos durante a coleta porta a porta e pelas catadoras, que encenam um teatro sobre a importância da coleta seletiva para o meio ambiente e toda cidade. Porém, há que se destacar que as cooperadas entrevistadas dizem que o trabalho possui suas restrições, visto não haver recursos suficientes para sua correta e regular execução. Na visão da cooperada Vera a mobilização social deveria ser mais constante, assim como outras efetuadas pela prefeitura. Para a cooperada Madalena: "A mobilização podia ser mais frequente. Ter apoio de uma rádio. Tem mobilização constante sobre a dengue, sobre outras coisas, então, eu acho que deveria ter da reciclagem também”.

A remuneração pelo contrato de prestação de coleta seletiva garante a todos os catadores acesso a garantias sociais como inserção de todos eles na condição de segurados do Instituto Nacional do Seguro Social (INSS) e, consequentemente, todos os benefícios advindos disso, como auxílio maternidade e auxílio doença. "Se você machucar, acontecer alguma coisa, tem INSS que te cobre" (COOPERADA VERA); "Licença maternidade!" (COOPERADA MADALENA); "No lixão você não tinha nada disso. Lá se você machucou o problema era seu. Você amarrava um pano e continuava trabalhando (COOPERADA VERA)".

O contrato permite que os custos de manutenção da Cooperativa sejam cobertos sem a retirada de recursos provenientes da venda dos recicláveis, o que não acontecia antes de seu estabelecimento, mesmo com a Cooperativa já instituída.

A gente não se vê sem esse contrato, porque não dá conta de viver sem esse contrato, pagar as despesas, funcionários, não tem como. Ele não é nem um contrato: ahh, você recebem da prefeitura. Não! É tudo daqui. O nosso é o que nós fazemos. Nosso material! (COOPERADA VERA). 
Além de todas as melhorias sociais, o trabalho em cooperativa permitiu o acesso à política pública do governo do estado de Minas Gerais, a Bolsa Reciclagem, que oferece às cooperativas devidamente constituídas repasses monetários trimestrais pelos serviços ambientais que elas promovem com a coleta seletiva. Ou seja, mais uma fonte de renda e possibilidade de recursos para investimentos.

\section{Desafios para uma coleta seletiva mais eficiente}

O principal conflito levantado pela pesquisa diz respeito à relação entre a Cooperativa e a Secretaria de Obras e Serviços Públicos e estas duas com a população de Nepomuceno. A Secretaria de Obras e Serviços Públicos não dispõe do entendimento de que o município, ao reconhecer em seu Código de Postura a promoção da remoção do lixo domiciliar, incentivando a coleta seletiva, também está cumprindo um princípio da PNRS que é a participação dos catadores nas atividades de coleta seletiva. Para o Secretário, a Prefeitura atua apenas no sentido de ajudar, de forma assistencialista, a Cooperativa, não a enxergando como uma parceira, executora de parte da Limpeza Urbana do Município.

porque o certo é viver com a perna deles, não precisar da prefeitura pagar. A prefeitura ainda tem que pagar um tanto por mês. Quando a prefeita começou o mandato dela, tava pagando até 22 mil reais por mês pra eles, o que não era justo. Eles vendem aquilo, eles têm que viver é daquilo lá, a cooperativa é pra isso. (SECRETÁRIO DE OBRAS E SERVIÇOS PÚBLICOS).

Neste quadro, o serviço de utilidade pública prestado pela RECICLANEP é encarado como um auxílio. Nesta perspectiva, o rompimento com a visão de que, por serem os catadores pessoas advindas de um processo anterior de exclusão, a contratação da RECICLANEP seja uma política assistencial. Assim, no Município, as coletas que deveriam ser complementares passam a se tornar conflitantes. No início do ano de 2017, sem prévio aviso à população e discussão com a Cooperativa, a Secretaria de Obras e Serviços Públicos alterou o horário da coleta convencional, causando, segundo os catadores entrevistados, uma enorme confusão para a população, que passou a dispor os recicláveis juntamente com os resíduos da coleta convencional.

Preocupadas com a diminuição no volume de material reciclável, os catadores procuraram a Secretaria de Agricultura e Meio Ambiente, na tentativa de resolução da questão. Questionaram por que, à época, haviam sidos produzidos fôlderes apenas para informar o horário da coleta convencional e solicitaram que fossem feitos outros para 
divulgação da coleta seletiva. O pedido foi atendido e, além dele, foi realizada uma reunião na Prefeitura Municipal no segundo semestre de 2017. Participaram os catadores, o Secretário de Agricultura e Meio Ambiente, além de todos os garis e motoristas executores da coleta convencional. A reunião teve por objetivo a realização de uma intervenção dialógica na perspectiva de Freire (2013) e na concepção da construção do conhecimento por meio do compartilhamento entre pessoas de Coelho (2014). Foi mediada pela pesquisadora com o objetivo de debater a necessidade de cooperação entre os dois tipos de coleta de resíduos no município. Observou-se, durante a reunião, o interesse dos garis em entender o que seria reciclável e não reciclável. Os diálogos entre eles e os catadores não demonstraram nenhuma animosidade entre as partes.

De acordo com a Cooperada Vera, após a reunião, os garis passaram a não coletar os resíduos recicláveis, no entanto, esta ação não se prolongou. Ela argumenta que, este conflito sempre existirá porque os garis recebem ordens de seus chefes na Secretaria de Obras e Serviços Públicos para coletarem qualquer material disposto.

Perguntadas se existe algum conflito entre Cooperativa e a Prefeitura, as cooperadas Vera e Madalena responderam:

Ah, isso aí na minha visão sempre vai ser um conflito. Nós já tivemos aquela reunião junto com eles. Eles [garis] pararam de catar o material reciclável e nós passamos a coletar dois caminhões, depois voltou tudo a ser como era antes. (COOPERADA VERA).

A ordem que vem da Prefeita e de outros é já deixar o nosso material, só que tem aqueles ignorantes, aquelas pessoas ignorantes que não pensa no outro, que não tá nem aí, porque trabalhando ou não o deles tá lá. (COOPERADA MADALENA).

A Secretaria de Obras e Serviços Públicos argumenta ser a pressão da sociedade o principal motivo por recolherem materiais recicláveis na coleta convencional.

Às vezes eles [Cooperativa] reclamam que nós estamos pegando material que é deles. Aí eu já recomendo para deixar o que for papelão. Acontece que quando acumula eu tenho que pegar. A população reclama. (SECRETÁRIO DE OBRAS E SERVIÇOS PÚBLICOS).

Esta pressão também é relatada pela Secretaria de Agricultura e Meio Ambiente que afirmou entender que, para a Cooperativa, a não separação dos resíduos é perda de recursos, mas também argumentou entender a pressão que a sociedade faz para o recolhimento dos resíduos de suas residências. Para ele, a resolução deste conflito está em ações de educação 
ambiental para conscientização da sociedade a separar na fonte os resíduos recicláveis e não recicláveis, além de dispô-los nos horários corretos de cada uma das coletas.

O Secretário de Obras e Serviços Públicos acredita que, para melhoria do problema com a sociedade, a Cooperativa deve aumentar o turno da coleta seletiva na cidade, enxergando apenas suas limitações operacionais, apesar de reconhecer que há limitações financeiras tanto da Cooperativa quanto da Prefeitura para disponibilização de mais motoristas e mais combustível para o caminhão da coleta seletiva.

A Cooperada Maria compactua, em parte, com a visão dele, mas acredita que sem o apoio da população o conflito não poderá ser solucionado. Sem as ações de educação ambiental que ela, bem como o biólogo também acreditam ser responsabilidade da Prefeitura, de modo algum somente a ampliação dos turnos da coleta seletiva conseguirá garantir maior quantidade de material à cooperativa.

Para todos os catadores, os garis e motoristas que atuam na coleta convencional, poderiam ser parceiros da Cooperativa, caso suas chefias considerassem a importância da coleta seletiva para o município e, principalmente, ao meio ambiente.

Diante dos fatos narrados, todas as evidências corroboram para a existência de um conflito na parceria entre a Cooperativa e Prefeitura estar envolto de uma pressão da sociedade, o que não descarta também a visão equivocada da Secretaria de Obras e Serviços Públicos a respeito da participação da Cooperativa na gestão dos resíduos sólidos.

\section{Perspectivas para o futuro da gestão de resíduos sólidos no município de Nepomuceno com a inclusão dos catadores}

O lixão municipal foi fechado definitivamente no mês de outubro de 2018 , sendo cessada, de forma definitiva, a ida dos catadores até ele. Desta data em diante, a Prefeitura, segundo o biólogo da Secretaria Municipal de Agricultura e Meio Ambiente, encontrou como forma econômica mais viável para dispor o lixo não reciclável a realização de um processo licitatório municipal na modalidade de pregão presencial para contratação de empresa de tratamento de resíduos para dispô-los de forma ambientalmente adequada, em conformidade com a PNRS (BRASIL, 2010). A empresa vencedora foi a SERQUIP tratamento de resíduos. Desde outubro de 2018, todo resíduo coletado pela coleta de lixo convencional do município, notadamente a parte de resíduos não recicláveis, tem sido enviado para ela através de outra empresa, também contratada via licitação, para realizar o transbordo dos rejeitos (não recicláveis). 
Discussões têm sido feitas para que seja encontrada a forma mais viável de inativar o lixão de forma a não causar danos ao meio ambiente. O Ministério Público continua cobrando e estabelecendo prazos para consecução desta ação e, por isso, em 14 de janeiro de 2019, outro Termo de Ajustamento de Conduta foi estabelecido entre Prefeitura e o Ministério Público, que determinou prazos e medidas para essa inativação, além da necessidade de elaboração de um Plano Municipal de Gestão Integrada de Resíduos Sólidos e incentivo à coleta seletiva e inclusão social dos catadores de materiais recicláveis, inclusive aqueles informais, ainda não pertencentes à cooperativa. Na cidade, é possível observar o trabalho de carroceiros que fazem a coleta de materiais recicláveis de maneira informal.

Para ampliação da coleta seletiva, no sentido de aumentar a participação social da população na separação do material reciclável e também oferecer maiores subsídios técnicos para a prefeitura e catadores, a Secretaria Municipal de Meio Ambiente pesquisou editais na área de meio ambiente. Deparando-se com o Edital da Fundação Estadual de Meio Ambiente $(\text { FEAM })^{8}$, que selecionava municípios para receber apoio técnico do Estado de Minas Gerais para implantação ou ampliação da coleta seletiva. Nepomuceno foi uma das cidades contempladas $^{9}$ com o apoio técnico do Instituto GESOIS, em parceria com a FEAM na busca de melhorias para a coleta seletiva e toda gestão dos resíduos sólidos.

As ações executadas pelo Instituto GESOIS permitiram a elaboração de um diagnóstico sobre a disposição dos resíduos no município, com foco nas potencialidades e desafios. Destaque para a execução do levantamento da composição gravimétrica dos resíduos no município, que verificou um potencial de recuperação destes de 30,12\%.

O programa foi lançado oficialmente no município em uma ação pública no dia 30 de dezembro de 2019, mas, logo depois, o Termo de Adesão ao apoio do Estado foi rescindido não sendo possível executar as ações de minimização e/ou correção das fragilidades levantadas.

O quarto aditivo ao Contrato de Prestação de Serviços de Coleta Seletiva entre a RECICLANEP e a Prefeitura de Nepomuceno foi assinado em 10 de janeiro de 2020 garantindo à cooperativa um repasse de $\mathrm{R} \$ 246.227,47$ e a continuidade de seu serviço ao município até 12 de janeiro de 2021.

\footnotetext{
8 Edital FEAM no01/2019. Disponível em: http://www.feam.br/images/stories/2019/EDITAIS/Edital_Coleta _Seletiva_minuta_para_PRO_SEI2-210119.doc. Acesso em: 11 mar. 2019.

9 Resultado do Edital FEAM no 01/2019. Disponível em: http://www.feam.br/images/stories/2019/EDITAIS/ RESULTADO_EDITAL_01-19_FEAM.pdf. Acesso em: 11 mar. 2019.
} 
A Secretaria de Agricultura e Meio Ambiente, em parceria com o Consórcio Nacional de Saneamento (CONSANE), um consórcio público ${ }^{10}$, do qual Nepomuceno é uma das nove cidades participantes, está elaborando o Plano Municipal de Gestão de Resíduos Sólidos, que se encontra na fase de consulta pública. Foram elaborados questionários para preenchimento da população. Toda divulgação aconteceu por meio de redes sociais. De acordo com o biólogo da Secretaria Municipal de Meio Ambiente, o plano será um instrumento de planejamento e controle, que permitirá um direcionamento de recursos mais eficiente. Questionado sobre quais seriam os possíveis benefícios do plano ele afirmou: "Traria isso que a gente tá tentando fazer: controlar quantidade produzida de resíduos, quantidade de reciclável, quantidade reaproveitada e zonear isso. Quem produz mais, comércio, indústria... assim recursos poderiam ser direcionados de maneira mais efetiva".

\section{Considerações finais}

O trabalho do INSEA junto à RECICLANEP viabilizou uma evolução no trabalho cooperativo e autogestionário que antes era competitivo e individual, além da inclusão da Cooperativa na rede de comercialização de recicláveis, que estabeleceu novas possibilidades de comercialização e, consequentemente, melhores preços de venda dos recicláveis.

O potencial de recuperação de resíduos, evidenciado pela análise gravimétrica, indica que são necessários maiores investimentos em mobilização social. Com maior quantidade de recicláveis coletados, maiores serão: a renda dos catadores e a economia da Prefeitura com o envio do material ao aterro sanitário da SERQUIP.

De forma geral, o trabalho demonstrou que os benefícios sociais aos catadores e catadoras e os benefícios econômicos, tanto para Cooperativa quanto a Prefeitura, estão estritamente correlacionados e se revertem em melhorias ambientais, portanto, maior sustentabilidade urbana. No entanto, o município ainda precisa romper alguns paradigmas em relação ao serviço prestado pela RECICLANEP e estabelecer de políticas públicas que insiram definitivamente a Cooperativa na Gestão Municipal de Resíduos Sólidos, de forma que as mudanças de gestão do município de Nepomuceno não possam representar riscos à manutenção do contrato de prestação de serviços de coleta seletiva.

\footnotetext{
${ }^{10}$ Disponível em: https://consane.mg.gov.br. Acesso em: 14 jul. 2020.
} 
Os esforços que estão sendo empreendidos desde a criação da Cooperativa levam ao entendimento de que a parceria RECICLANEP-Prefeitura de Nepomuceno está evoluindo no sentido de estabelecer, para o município, uma maior sustentabilidade na gestão dos resíduos sólidos que inclua socialmente os catadores.

\section{Referências}

ALBRELPE. Panorama dos resíduos sólidos no Brasil em 2018. Disponível em: http://albrelpe.org.br/download-panorama-2018-2019/. Acesso em: 26 maio de 2020.

BARDIN, L. Análise de conteúdo. São Paulo: Edições 70, 2016.

BESEN, G. R.; RIBEIRO, H. Panorama da coleta seletiva no Brasil: desafios e perspectivas a partir de três estudos de caso. Interfaces, São Paulo, v. 2, n. 4, p. 1-18, ago. 2007.

BRASIL. Decreto $n^{\circ} 5.940$, de 25 de outubro de 2006. Institui a separação dos resíduos recicláveis descartados pelos órgãos e entidades da administração pública federal direta e indireta, na fonte geradora, e a sua destinação às associações e cooperativas dos catadores de materiais recicláveis, e dá outras providências. Disponível em: http://www.planalto.gov.br/ ccivil_03/_ato2004-2006/2006/decreto/d5940.htm. Acesso em: 21 nov. 2018.

BRASIL. Lei $\mathrm{n}^{\circ} 11.445$, de 5 de janeiro de 2007. Estabelece as diretrizes nacionais para o saneamento básico; cria o Comitê Interministerial de Saneamento Básico; altera as Leis $\mathrm{n}^{\text {os }} 6.766$, de 19 de dezembro de $1979,8.666$, de 21 de junho de 1993 , e 8.987, de 13 de fevereiro de 1995; e revoga a Lei $\mathrm{n}^{\circ}$ 6.528, de 11 de maio de 1978. Disponível em: http://www.planalto.gov.br/ccivil_03/_ato2007-2010/2007/lei/111445.htm. Acesso em: 11 jul. 2017.

BRASIL. Lei $\mathrm{n}^{\mathrm{o}}$ 12.305, de 2 de agosto de 2010. Institui a Política Nacional de Resíduos Sólidos; altera a Lei no 9.605, de 12 de fevereiro de 1998; e dá outras providências. Disponível em: http://www.planalto.gov.br/ccivil_03/_ato2007-2010/2010/Lei/L12350.htm. Acesso em: 5 jul. 2017.

BRASIL. Lei $\mathrm{n}^{\circ}$ 8.666, de 21 de junho de 1993. Regulamenta o art. 37, inciso XXI, da Constituição Federal, institui normas para licitações e contratos da Administração Pública e dá outras providências. Disponível em: http://www.planalto.gov.br/ccivil_03/leis/L8666cons.htm. Acesso em: 10 jul. 2017.

BRASIL. Ministério do Desenvolvimento Regional. Secretaria Nacional de Saneamento SNS. Sistema Nacional de Informações sobre saneamento: diagnóstico do manejo de resíduos sólidos urbanos - 2018. Brasília: SNS/MDR, 2019. Disponível em: http://www.snis.gov.br/diagnostico-anual-residuos-solidos/diagnostico-do-manejo-deresiduos-solidos-urbanos-2018. Acesso em: 26 maio 2020.

CAREGNATO, R. C. A.; MUTTI, R. Pesquisa qualitativa: análise de discurso versus análise de conteúdo. Texto e Contexto Enfermagem, Florianópolis, v. 4, n. 15, p. 679-684, out./dez. 2006. Doi: 10.1590/S0104-07072006000400017. 
COELHO, F. M. G. A arte das orientações técnicas no campo: concepções e métodos. 2. ed. Viçosa: Suprema, 2014.

FRANÇA FILHO, G. C. de. A economia popular e solidária no Brasil. In: FRANÇA FILHO, G. C. de. Ação pública e economia solidária: uma perspectiva internacional. Porto Alegre: Editora da UFRGS. 2006. p. 259-268.

FREIRE, P. Extensão ou comunicação? Rio de Janeiro: Paz e Terra, 2013.

GIL, A. C. Métodos e técnicas de pesquisa social. São Paulo: Atlas, 2008.

IPEA - Instituto de Pesquisa Econômica Aplicada. Diagnóstico sobre catadores de resíduos sólidos. Brasília, 2012. Disponível em: http://www.silvaporto.com.br/admin/downloads/CATADORES_BRASIL_IPEA_2012.pdf. Acesso em: 13 jul. 2017.

IPEA - Instituto de Pesquisa Econômica Aplicada. Situação social das catadoras e catadores de material reciclável e reutilizável. Brasília, 2013. Disponível em: http://www.ipea.gov.br/agencia/images/stories/PDFs/situacao_social/131219_relatorio_situac aosocial_mat_reciclavel_brasil.pdf. Acesso em: 12 jul. 2017.

LIMA, F. de P. A. (org.). Prestação de serviços de coleta seletiva por empreendimentos de catadores: instrumentos metodológicos para contratação. Belo Horizonte: Insea, 2013.

MARTINS, R. S. O trabalho como princípio educativo: a experiência dos catadores de recicláveis do projeto Novo Ciclo. 2017. 114 f. Dissertação (Mestrado em Educação e Formação Humana) - Faculdade de Educação, Universidade Estadual de Minas Gerais, Belo Horizonte, 2017.

MEDEIROS, L. F. R. de; MACEDO; K. B. Catador de material reciclável: uma profissão além da sobrevivência? Psicologia e Sociedade, Porto Alegre, v. 18, n. 1, p. 62-71, ago. 2006. Doi: 10.1590/S0102-71822006000200009.

MNCR - Movimento Nacional dos Catadores de Materiais Recicláveis. A crise financeira e os catadores de materiais recicláveis. 2009. Disponível em: http://www.mncr.org.br/artigos/a-crise-financeira-e-os-catadores-de-materiais-reciclaveis. Acesso em: 22 abr. 2018.

MNCR - Movimento Nacional dos Catadores de Materiais Recicláveis. Carta de Brasília, 2001. Disponível em: http://www.mncr.org.br/sobre-o-mncr/principios-e-objetivos/carta-debrasilia. Acesso em: 12 jul. 2017.

MNCR - Movimento Nacional dos Catadores de Materiais Recicláveis. Disponível em: http://www.mncr.org.br/. Acesso em: 17 jul. 2017.

PEREIRA, M. C. G., TEIXEIRA, M. A. C. Inclusão de catadores em programas de coleta seletiva: da agenda local à nacional. Cadernos EBAPE.BR, Rio de Janeiro, v. 9, n. 3, p. 895-913, set. 2011. Doi: 10.1590/S1679-39512011000300011. 
PINHEL, J. R. (org.). Do lixo à cidadania: guia para a formação de cooperativas de catadores de materiais recicláveis. São Paulo: Pierópolis, 2013.

RIBEIRO, T. F.; LIMA, S. do C. Coleta seletiva de lixo domiciliar: estudo de casos. Caminhos de Geografia, Uberlândia, v. 1, n. 2, p. 50-69, dez. 2000.

SACHS, I. Desenvolvimento: includente, sustentável, sustentado. Rio de Janeiro: Garamond, 2008.

SANTOS, A. U. G. dos. et al. Oportunidades e desafios das organizações produtivas solidárias de coleta seletiva de um município do Triângulo Mineiro (MG). In: ENCONTRO NORDESTINO DE INCUBADORAS DE ECONOMIA SOLIDÁRIA/ENIES, 5., 2016, Juazeiro do Norte. Anais [...]. Juazeiro do Norte: Editora da UFCA, 2016. Disponível em: https://enies2016.wixsite.com/enies/gt-05. Acesso em: 9 jun. 2020.

SINGER, P.; SOUZA, A. R. A economia solidária no Brasil: a autogestão como resposta ao desemprego. São Paulo: Contexto, 2000.

TRIVIÑOS, A. N. S. Introdução à pesquisa em ciências sociais: a pesquisa qualitativa em educação. São Paulo: Atlas, 1987.

ZANIM, M.; GUTIERREZ, R. F. Panorama de empreendimentos econômicos solidários de catadores no Brasil. In: ZANIM, M; GUTIERREZ, R. F. (org). Cooperativas de catadores: reflexões e prática. São Carlos: Claraluz, 2011. p. 37-52.

Submetido em 15 de março de 2020.

Aprovado em 30 de junho de 2020. 